\title{
Entre España y América. La colección del prelado ilustrado Antonio Caballero y Góngora*
}

\author{
Between Spain and America. The collection of the \\ enlightened prelate Antonio Caballero y Góngora
}

\author{
Jesús María RUIZ CARRASCO \\ Departamento de Historia del Arte, Arqueología y Música. Universidad de Córdoba \\ https://orcid.org/0000-0001-6371-7437 \\ lg2rucaj@uco.es
}

\begin{abstract}
Antonio Caballero y Góngora was well known over the course of his career not only as a prelate, politician, and soldier in the Americas and in Spain, but also as a collector. He was the owner of a valuable and well-designed estate, consisting of a large library, a notable art collection, a series of diverse objects of singular value and an extraordinary numismatic collection, all demonstrating his ample curiosities and his identification with Enlightenment precepts. The characteristics of his property illustrate the development of collecting by Spanish elites during the Enlightenment era, and provide evidence of the antiquarian zeal of one of the most important ecclesiastical figures in the Hispanic world of this period
\end{abstract}

Keywords: Collecting, New Granada, Córdoba, Bishop.
Resumen: Antonio Caballero y Góngora destacó a lo largo de su carrera no sólo como prelado, político y militar en América y España, sino también como coleccionista. Fue dueño de un rico y razonado patrimonio que, evidenciando sus amplias inquietudes y su identificación con los preceptos ilustrados, estaba compuesto por una amplia biblioteca, una notable colección de arte, una serie de objetos diversos de singular valor y un extraordinario compendio numismático. Conjunto cuyas características exponen el devenir del coleccionismo español durante la época de la llustración y el afán recopilatorio de una de las figuras eclesiásticas más relevantes de dicho periodo en el ámbito hispánico.

Palabras clave: Coleccionismo, Nueva Granada, Córdoba, Obispo.

La progresiva implantación de los valores de la Ilustración en el conjunto de la Monarquía española a lo largo del siglo XVIII significó una importante renovación en los ámbitos político, social y cultural. La razón fue erigiéndose como fundamento principal de la legislación y del organigrama oficial, al igual que, en

* Este artículo forma parte de los resultados obtenidos en el marco del proyecto de doctorado financiado con una ayuda FPU por el Ministerio de Educación, Cultura y Deporte (MECD) (Referencia: FPU 15/02359), titulado «Cultura estética y Arquitectura de la Ilustración en Córdoba: el prelado Antonio Caballero y Góngora, el arquitecto Ignacio Tomás, la Escuela de Dibujo y la introducción de los preceptos artísticos academicistas», y dirigido por Roberto González Ramos. 
paralelo, la promoción de las diferentes ramas del conocimiento protagonizó la actividad y las inquietudes de las élites sociales. Así, durante este periodo, la notoriedad de los individuos no sólo se midió por su posición o clase, sino también por su nivel cultural. En este contexto, las colecciones privadas pasaron de ser un compendio de objetos de valor destinados únicamente al deleite personal o a la escenificación del poder, a representar también la cultura del sujeto desde un punto de vista ilustrado. La voluntad por conocer la Historia, apreciar el Arte, adquirir nociones de carácter científico o dominar las diferentes ramas del saber desde la razón, impulsó la reunión reflexiva de conjuntos de bienes pensados para el desarrollo intelectual de los individuos y la escenificación social de su erudición. Este fue el caso de Antonio Caballero y Góngora, un hidalgo que, a pesar de no pertenecer a una familia de especial relevancia, compendió a lo largo de su dilatada y exitosa carrera como eclesiástico una valiosa y variada colección, representativa del alto nivel cultural e intelectual por el que fue ampliamente reconocido entre sus contemporáneos. Una colección cuyo contenido, a la altura del que fue una de las figuras más sobresalientes de la segunda mitad del siglo XVIII español en los ámbitos religioso, político, cultural y militar, es objeto de estudio en el presente artículo.

\section{UNA TRAYECTORIA AL SERVICIO DE LA IGLESIA Y DEL REY}

Nacido en Priego de Córdoba el 23 de mayo de 1723, Antonio Caballero y Góngora se trasladó en 1738 a Granada, donde inició sus estudios universitarios por medio de una beca de Teología en el Real Colegio de San Bartolomé y Santiago hasta $1743^{1}$. Ese mismo año consiguió por oposición otra beca en el Real Colegio Mayor de Santa Catalina de la ciudad granadina, graduándose como licenciado en Teología en julio de $1744^{2}$. Continuó sus estudios en el citado centro, donde se especializó en Teología Dogmática, Escolástica y Moral hasta su nombramiento como presbítero el 15 septiembre de $1750^{3}$. Inició entonces su carrera eclesiástica. Primero, presentándose con éxito a una capellanía vacante de la Capilla Real de Granada el 13 de noviembre de 1750; y, tras

1 Tomás Gómez y Gómez, Vida y obra de Don Antonio Caballero y Góngora, Sevilla, 1989, pp. 7-9.

2 José Manuel PÉREZ AYala, Antonio Caballero y Góngora. Virrey y Arzobispo de Santa Fé. 1723-1796, Bogotá, 1951, pp. 18-19.

3 José María ReY Díaz, D. Antonio Caballero y Góngora. Arzobispo-Virrey de Nueva Granada (I), en Boletín de la Real Academia de Ciencias, Bellas Artes y Nobles Artes de Córdoba, 4 (1923), p. 71. 
casi tres años en dicho cargo, optando y ganando la oposición de la canonjía lectoral de la Catedral de Córdoba, de la que tomó posesión el 29 de noviembre de $1753^{4}$.

A lo largo de este periodo de más de veinte años, además de por su dedicación al Cabildo catedralicio, sus cualidades personales, sus muestras públicas de humildad, sus obras de caridad y su consagrada fama como orador dentro y fuera de la ciudad cordobesa ${ }^{5}$, el canónigo cordobés sobresalió por su afán coleccionista. Caballero y Góngora, que residió prácticamente toda esta etapa de su vida en el convento de San Felipe Neri de Córdoba en unas condiciones aparentemente austeras, invirtió los caudales de su canonjía casi exclusivamente en la recopilación del grueso de su colección, denominada por él mismo como su «museo» ${ }^{6}$. $\mathrm{Y}$ es que, aunque se desconocen mayoritariamente los métodos por los que el prebendado reunió tal conjunto de bienes, la recopilación del mismo durante este periodo evidencia sus estimables recursos, contactos e inquietudes históricoartísticas, que compaginó con su cometido oficial.

La fama de Caballero y Góngora alcanzó tales cotas que gozó tanto del favor popular, como del reconocimiento de las figuras más preeminentes de la época. También del Rey, quien le promocionó como obispo de Mérida de Yucatán el 17 de mayo de $1775^{7}$. Dicha etapa resultó breve, pues el Monarca promovió el 19 de septiembre de 1777 su nombramiento como arzobispo de Santa Fé de Bogotá, cuya prelatura ocupó el 24 de marzo de $1779^{8}$. A partir de entonces y, sobre todo, desde su nombramiento como virrey, gobernador y capitán general de Nueva Granada, así como presidente de la Real Audiencia de Santa Fé el 15 de junio de 1782, centró sus esfuerzos en corresponder con las funciones administrativas, políticas y militares de sus cargos ${ }^{9}$.

4 José Luis MORA MÉRIDA, Ideario reformador de un cordobés ilustrado: el Arzobispo y Virrey don Antonio Caballero y Góngora, en Bibiano TORREs RAMíREZ y Jose J. HERnández PALOMO (coords.), Andalucía y América en el siglo XVIII: actas de las IV Fornadas de Andalucía y América, 2 t., Sevilla, 1985 , t. 2, pp. 233-260.

5 Francisco de Paula TOledANO, Oración panegírica, e historial, en justa memoria del Excmo. è Illmo. Señor Don Antonio Caballero y Gongora, Granada, 1798, pp. 11-13.

6 Fernando José de Velasco y CEBALlos, Documentos y correspondencia sobre numismática. Ms. Madrid, Biblioteca NACIONAL DE EsPaÑa [=BNE], Mss/2537, ff. 31r-34r.

7 José María Rey DíAZ, D. Antonio Caballero y Góngora. Arzobispo-Virrey de Nueva Granada (II), en Boletín de la Real Academia de Ciencias, Bellas Artes y Nobles Artes de Córdoba, 5 (1923), pp. 5-33.

8 José Manuel Pérez Ayala, Antonio Caballero... [ver n. 2], pp. 49-50.

9 Caballero y Góngora también fue condecorado con la Gran Cruz de la Real y Distinguida Orden de Carlos III el 3 de mayo de 1782. Véase, entre otros títulos (además de los ya citados), lo referido en Víctor FrANKL, La filosofía política del Arzobispo-Virrey de Nueva Granada Antonio 
La intensa dedicación que le exigió el desempeño de sus cometidos propició que, ya anciano, presentara la renuncia a los mismos en dos ocasiones. La última de ellas fue aceptada en abril de 1788 por Carlos III $^{10}$, quien, además, le promocionó para ocupar la prelatura vacante del Obispado de Córdoba ${ }^{11}$. Tras un largo viaje, Caballero y Góngora llegó el 19 de diciembre de 1789 a Córdoba, donde ejerció como «arzobispo obispo» de su Diócesis hasta el 24 de marzo de $1796^{12}$, cuando aconteció el óbito del prelado ${ }^{13}$.

Tras su defunción, se redactaron 209 cuadernos de espolios pertenecientes a la prelatura de nuestro protagonista, entre los que se encuentran varios referentes a sus bienes. Estos documentos, ya sea por su carácter inédito o por su comparación con otros ya publicados, han permitido esclarecer definitivamente la composición de la colección de Caballero y Góngora, la lista de aquellos objetos que dejó en América, los que reunió allí y la totalidad de los que trajo a Córdoba. Una colección que, según la clasificación establecida en la referida documentación, se detalla a continuación.

\section{FUENTES PARA EL CONOCIMIENTO DE UN ERUDITO ILUSTRADO: LA BIBLIOTECA}

El análisis de la biblioteca es fundamental para entender la personalidad y los intereses de Antonio Caballero y Góngora. Sus libros son los elementos más representativos de las inquietudes, de las preocupaciones y de la cultura de un

Caballero y Góngora, en Bolívar, 1 (1951), pp. 113-129; ID., La estructura barroca del pensamiento político, histórico y económico del Arzobispo-Virrey de Nueva Granada Antonio Caballero y Góngora, en Bolivar, 5 (1951), pp. 805-873; ID., La filosofía social tomista del arzobispo-virrey del Nuevo Reino de Granada, Caballero y Góngora y la de los comuneros colombianos, en Bolívar, 15 (1952), pp. 595 626; Roberto María TISNES JimÉNEZ, Caballero y Góngora y los Comuneros, Bogotá, 1984; Nelson Eduardo RoDRÍGUEZ, El imperio contraataca: las expediciones militares de Antonio Caballero y Góngora al Darién (1784-1790), en Historia Crítica, 53 (2014), pp. 201-223.

10 Simancas, ARChivo General de Simancas, Secretaria de Estado y del Despacho de Guerra, Francisco Gil Lemos: Virrey, 7083-1, exp. 3, s/f.

11 José María REY DíAZ, D. Antonio Caballero... [ver n. 7], p. 25.

12 Durante dicho periodo Caballero y Góngora destacó por dedicar gran parte de sus esfuerzos a la promoción artística. Labor por la que la Real Academia de Bellas Artes de San Fernando de Madrid le concedió el título de «Académico de Honor» el 5 de agosto de 1792. MADRID, ARCHIVO DE la REAl ACADEMIa DE BEllas ARTES DE SAN FERNANDo [=ARABASF], Secretario General, Académicos de Honor, Nombramientos, 1-40-5, s/f.

13 Actas capitulares de la Catedral de Córdoba del día 24 de marzo. CórdobA, ARCHIVo DE LA CaTedral de CóRdoba, Actas Capitulares, 94, ff. 251v-252v. 
personaje ampliamente reconocido entre sus contemporáneos por su elocuencia y erudición. En este sentido, cabe destacar la variedad temática de los títulos que componen este notable elenco, cuyo contenido no sólo presenta a su dueño como un destacado personaje ilustrado dedicado al estudio de las diferentes ramas del conocimiento o muestra sus principales intereses ${ }^{14}$, sino que también explica en gran medida el resto de su colección, relacionada directamente con el contenido de su biblioteca. Este conjunto de títulos fue legado en su mayoría al Arzobispado de Santa Fé de Bogotá en 1788, si bien la documentación antes referida ha permitido desvelar que una selección del total de los volúmenes que poseía Caballero y Góngora fueron traídos a Córdoba, con el fin de mantenerlos cerca durante el último periodo de su vida. Por tanto, el análisis de la biblioteca de nuestro protagonista merece ser dividido en tres apartados: uno concerniente a la totalidad de la misma, otro relativo a los volúmenes que dejó en América y el último, el más interesante por su carácter inédito, referente a los traídos a Córdoba.

La biblioteca personal de Antonio Caballero y Góngora estaba compuesta antes de su vuelta a la Península Ibérica por un total de 464 títulos, divididos en 1.162 volúmenes de diferentes formatos ${ }^{15}$. Este compendio de obras destacó cuantitativamente como uno de los más relevantes entre los existentes no sólo en el Virreinato de Nueva Granada ${ }^{16}$, sino también en los reinos españoles de la Península Ibérica ${ }^{17}$. De hecho, se encuentra entre las bibliotecas más destacadas de cuantas pertenecieron a las figuras eclesiásticas hispánicas más sobresalientes de

14 Sobre la importancia del «gusto» en el siglo XVIII a través de las bibliotecas privadas de los individuos véase María Luisa LÓPEZ-VIDRIERO, El Gabinete de un hombre de gusto. Manuales para la formación de bibliotecas en el siglo XVIII, en María Luisa LÓPEZ-VIDRIERO y Pedro M. CÁTEDRA (dirs.), El Libro Antiguo Español IV. Coleccionismo y bibliotecas (siglos XV-XVIII), Salamanca, 1998, pp. 447-460.

15 La cantidad expuesta es la suma de los inventarios contenidos en José TORRE REVELLO, La biblioteca del virrey-arzobispo del Nuevo Reino de Granada Antonio Caballero y Góngora, 1788, en Boletín del Instituto de Investigaciones Históricas, 41 (1929), pp. 27-45, y en CóRDOBA, ARCHIVO GENERAL DEL OBISPADO DE CÓRDOBa [=AGOC], Expolios, 9647, exp. 2, ff. 25r-26r.

16 La más importante en dicho territorio tras la perteneciente a Antonio Nariño, tal y como se expone en Renán Silva, Los ilustrados de Nueva Granada, 1760-1808, Medellín, 2002, pp. 279-311.

17 Siguiendo la estela de las bibliotecas privadas españolas más importantes de la segunda mitad del siglo XVIII, tales como las pertenecientes al conde del Águila, Gaspar Melchor de Jovellanos o Sebastián Martínez. Así como superando o igualando a otras del mismo periodo, como la existente en posesión de Pablo de Olavide. Dichas bibliotecas, entre otras de la época referida en el ámbito hispánico, aparecen mencionadas y desarrolladas en Luis Miguel ENCISO RECIO, Barroco e Ilustración en las bibliotecas privadas españolas del siglo XVIII, Madrid, 2002, pp. 147-212. 
la segunda mitad del siglo XVIII ${ }^{18}$. La clasificación temática de la biblioteca también evidencia su calidad. Pues, si bien prevalecen en ella las publicaciones de temática religiosa (incluida la Historia de la Iglesia) y teológica con un total de 177 títulos (37,3\%), también la conforman diversos grupos de obras pertenecientes a otras materias. Siguiendo un orden cuantitativo, el segundo de los apartados es el concerniente a Lengua, Literatura y Dialéctica, que suma 131 títulos (28,2\%); seguido de las secciones de Historia (excluyendo la Historia de la Iglesia) y viajes, con 43 obras (9,3\%); Política, Sociedad, Nobleza y Justicia, con 23 (4,9\%); Agricultura, Ganadería, Industria y Minería con otros 23 (4,9\%); temática bélica, naval y relativa a las Indias occidentales, con 22 (4,7\%); Filosofía, con 21 (4,5\%); Ciencia, con 17 (3,6\%); y, por último, la dedicada a Arte, Arquitectura y Numismática, con 11 títulos $(2,4 \%)^{19}$. Asimismo, aunque la lengua predominante de los títulos que integraban el total de la biblioteca era el castellano (51,5\%), también formaban parte de la misma una gran cantidad de obras redactadas en francés $(26,2 \%)^{20}$ y en latín $(22,2 \%)$.

Como ya se ha aludido previamente, el 29 de noviembre de 1788, antes de embarcar hacia la Península Ibérica para ocupar la prelatura de la Diócesis de Córdoba, Caballero y Góngora donó un total de 409 títulos (1.036 volúmenes) de su biblioteca personal al Arzobispado de Santa Fé de Bogotá ${ }^{1}$. Un suceso excepcional pero no aislado, puesto que tuvo como precedente el protagonizado por Francisco Antonio de Lorenzana, quien, tras haber ocupado la prelatura del Arzobispado de México, legó su biblioteca personal al Real Pontificio Seminario

18 Véanse otros ejemplos de otras bibliotecas pertenecientes a clérigos españoles del siglo XVIII en Inmaculada ARIAS DE SAAVEDRA ALÍAS, Libros, lectores y bibliotecas privadas en la España del siglo XVIII, en Chronica Nova, 35 (2009), pp. 15-61. Asimismo, véanse los relevantes datos aportados al respecto por Francisco Javier BURGOS RINCÓN, Los libros privados del clero: La cultura del libro del clero barcelonés en el siglo XVIII, en Manuscrits: Revista d'bistoria moderna, 14 (1996), pp, 231-258.

19 Conviene reseñar que la división temática expuesta sobre la biblioteca de Antonio Caballero y Góngora difiere de una ya publicada, puesto que en la misma se clasificaron las materias de otro modo al expuesto aquí y no se pudo incluir el listado de libros llevados a Córdoba en 1789. La división antes referida aparece contenida en Renán SILVA, Los ilustrados... [ver n. 16], p. 297.

20 Teniendo en cuenta el contexto cultural de la segunda mitad del siglo XVIII, era habitual que los ilustrados culturalmente más reconocidos compendiaran gran parte de su biblioteca en francés. Véase Jacques SOUBEYROUX, La biblioteca de Campomanes: contexto cultural de un ilustrado, en Actas del Séptimo Congreso de la Asociación Internacional de Hispanistas, 2 t., Roma, 1982, t. 2, pp. 9971006; Inmaculada ARIAS DE SAAVEDRA ALÍAS, Libros extranjeros en bibliotecas privadas españolas del siglo XVII, en Agustín GUIMERá RaVINA y Víctor PERALTa RUIZ (coords.), Actas de la VIII Reunión Científica de la Fundación Española de Historia Moderna, 2 t., Madrid, 2005, t. 2, pp. 395-416.

21 José TORRE Revello, La biblioteca... [ver n. 15], pp. 27-45. Reseñado íntegramente en Jose Manuel PÉREZ AYALA, Antonio Caballero... [ver n. 2], pp. 285-295. 
de la ciudad mexicana antes de su traslado a Toledo ${ }^{22}$. Dadas las singulares circunstancias de ambos casos no se puede asegurar que estemos ante una práctica habitual, aunque nos sirven para advertir la preocupación de estas dos destacadas personalidades eclesiásticas de la Ilustración española por la divulgación del conocimiento al otro lado del Atlántico ${ }^{23}$. Igualmente, la cesión mayoritaria de la biblioteca privada de Caballero y Góngora al Arzobispado de Santa Fé de Bogotá significó la culminación de un proceso centrado en la mejora de las infraestructuras del mismo ${ }^{24}$. Y es que, como podrá comprobarse también más adelante, nuestro protagonista utilizó parte de su patrimonio como instrumento al servicio de los valores ilustrados, ya que no sólo lo compiló y destinó a aumentar y escenificar su nivel cultural, sino que también lo cedió, legó y empleó para beneficiar el desarrollo del conocimiento.

El porcentaje de materias y de lenguas de los 409 títulos donados al Arzobispado de Santa Fé de Bogotá es muy similar al total de los que poseía Caballero y Góngora. Entre los 153 títulos $(37,4 \%)$ de temática religiosa y teológica destaca el gran número de ellos en lengua francesa, tales como Histoire Ecclésiastique (36 volúmenes) ${ }^{25}$, Dictionnaire Apostolique (12 volúmenes) ${ }^{26}$ o Bibliotbèque des Prédicateurs (21 volúmenes) ${ }^{27}$, además de otros en latín y castellano. Al margen del gran compendio de obras de Literatura clásica y española (las cuales, junto a los títulos de Gramática y Dialéctica, componen el 28,6\%), los volúmenes pertenecientes a Historia y viajes $(9,7 \%)$ y los de Filosofía (5,1\%), merecen especial atención aquellos dedicados a la Política, la Sociedad, la Nobleza y la Justicia $(5,4 \%)$. En este último grupo se encuentran obras como Obligaciones de los Amos

22 Donde ocupó la prelatura de su Arzobispado a partir de 1772. Cándido DE LA CRUZ ALCAÑIZ, La imagen del Arzobispo y Cardenal Francisco Antonio de Lorenzana, en Archivo Español de Arte, 329 (2010), pp. 41-60.

23 Para más información sobre la figura Francisco Antonio de Lorenzana y su época véase Luis SiERRA NAVA-LASA, El Cardenal Lorenzana y la Ilustración, Madrid, 1975; Jesús PANIAGUA PÉREZ (coord.), España y América entre el Barroco y la Ilustración (1722-1804). II Centenario de la muerte del Cardenal Lorenzana, León, 2005.

24 ARABASF, Secretario General, Académicos, Comunicaciones de fallecimientos y notas necrológicas, 1-47-2, Antonio Caballero y Góngora, f. 9r.

25 Correspondientes probablemente a la edición de Claude FLEURY, Histoire ecclésiastique, 36 t., Paris, 1719-1734.

26 Teniendo en cuenta lo contenido en Jean-Baptiste GLAIRE, Dictionnaire Universel des Sciences Ecclésiastiques, 2 t., Paris, 1868, t. 2, p. 1525, probablemente se trate de la edición correspondiente a Hyacinthe de Montargon, Dictionnaire Apostolique, 13 t., Paris, 1752-1758, por lo que los pertenecientes a Caballero y Góngora estarían incompletos.

27 Vincent Houdry, La Bibliothèque des Prédicateurs, 21 t., Lyon, 1724-1743. 
$y$ de los Criados $^{28}$, Instruccion a los Principes ${ }^{29}$ o Discours Politiques ${ }^{30}$. Igualmente, entre los títulos dedicados a la Agricultura, Ganadería, Industria y Minería $(5,4 \%)$ destacan Éléments d'Agriculture ${ }^{31}$ o De re metallica ${ }^{32}$. Por otro lado, el apartado dedicado a Guerra, Navegación e Indias $(3,6 \%)$ esta compuesto por títulos como Histoire Navale d'Angleterre (3 tomos) ${ }^{33}$, Trigonometria aplicada a la Navegacion ${ }^{34}$ o Noticia de la California (3 tomos) ${ }^{35}$; y el correspondiente a Ciencia $(3,4 \%)$ por obras como Philosophiae Naturalis Principia Mathematica (4 tomos) ${ }^{36}$, Compendio Mathematico (9 tomos) $)^{37}$ u Observaciones astronómicas hechas en Cádiz (2 tomos) ${ }^{38}$. Por último, cabe destacar los 5 títulos que componían la rama de Arte, Arquitectura y Numismática $(1,2 \%)$, que si bien no destacan en cantidad, sí lo hacen por su originalidad. Pues, salvo el caso de un volumen denominado textualmente como «Vitruvij architect» ${ }^{39}$, referente con toda seguridad a Los Diez Libros de Arquitectura de Marco Vitruvio Polión ${ }^{40}$, las otras cuatro obras de este aparta-

28 Que demuestra la predilección de Antonio Caballero y Góngora por las obras de Claude Fleury. Teniendo en cuenta lo contenido en el inventario, se trataría de la edición en castellano. Véase Manuel MARTÍNEZ, Obligaciones de los Amos y de los Criados, escritas en francés por el mui ilustre señor Claudio Fleuri, Madrid, 1771.

29 La pertenencia de este título escenifica la relevante relación entre Caballero y Góngora y los jesuitas (ya expuesta en Manuel PeláEZ DEL Rosal, José María REY DíAZ y Roberto María Tisnes JimÉnEZ, El Obispo Caballero, un prieguense en América, Priego de Córdoba, 1989, p. 20), teniendo en cuenta el contenido de la publicación mencionada. Instrucción a los Principes, sobre la política de los Padres jesuitas, Madrid, 1768.

30 Nuevamente se constata la importancia otorgada por Caballero a los textos franceses, sobre todo en lo relativo a los campos político, religioso y social. RICHELIEU, Le politique tres-christien ou Discours politiques, Paris, 1645.

31 Obra de Henri-Louis Duhamel du Monceau, autor del que Caballero y Góngora poseía varios títulos. DuHamel de MONCEAU, Éléments d'Agriculture, 2 t., Paris, 1762.

32 Georgii AgRICOLAE, De re metallica, Basilea, 1561.

33 Thomas LEDIARD, Histoire Navale d'Angleterre, Lyon, 1751.

34 Pedro Manuel CEDILlo, Trigonometria aplicada a la Navegacion, Sevilla, 1718.

35 Miguel Venegas, Noticia de la California y de su conquista temporal y espiritual hasta el tiempo presente, Madrid, 1757.

36 Isaac NeWTON, Philosophiae Naturalis Principia Mathematica, Londres, 1726.

37 Thomas Vicente TosCA, Compendio Mathematico, en que se contienen todas las materias mas principales de las Ciencias, que tratan de la Cantidad, 9 t., Valencia, 1757.

38 Vicente TOFIÑO DE SAN Miguel, Observaciones astronómicas hechas en Cádiz, en el obsertario Real de la Compañía de Cavalleros Guardias-Marinas, Cádiz, 1776.

39 Un título que ya fue reseñado con cierta sorpresa en José TORRE REvELLO, Tratados de Arquitectura utilizados en Hispanoamérica (siglos XVI a XVIII), en Revista interamericana de bibliografía, 6 (1956), pp. 3-23.

40 Teniendo en cuenta la referencia al título contenida en el inventario que nos ocupa y la capacidad de Caballero y Góngora para recopilar ediciones francesas poco frecuentes en el ámbito hispánico, es probable que estemos ante la edición de Guillaume PHILANDrIER, M. Vitruvij Polionis De Architectura Libri X, Lyon, 1552. 
do resultan especialmente llamativas: Numismata Graeca ${ }^{41}$, Historia numismática Ptolemaeorum $^{42}$ e Historia numismática Regum Syriae ${ }^{43}$ de Jean Foy-Vaillant ${ }^{44}$, y Discursos sobre la ingenuidad del Arte de la Pintura ${ }^{45}$. Un legado bibliográfico que escenifica las amplias inquietudes de un individuo centrado en la búsqueda y la difusión del conocimiento en general desde un punto de vista puramente ilustrado, tal y como se percibe del listado de los datos y de los ejemplos que se han aportado hasta el momento.

El conjunto de títulos cedidos al Arzobispado de Santa Fé de Bogotá no componían la totalidad de la biblioteca personal de Antonio Caballero y Góngora, como se creía hasta el momento, ya que trasladó a Córdoba una selección de 55 títulos (160 volúmenes) de los que quiso disponer durante la última etapa de su vida ${ }^{46}$. En concreto, el Prelado llevó a Córdoba 19 títulos de temática religiosa; 13 de Lengua y Literatura; 8 relacionados con la Guerra, la Navegación y las Indias occidentales; 6 de Numismática; 3 de Historia; 2 de Ciencia; 2 de Arquitectura e Ingeniería; la «Ordenanza para cria de caballos» ${ }^{47}$; y las Constituciones de la Real y Distinguida Orden Española de Carlos Tercero ${ }^{48}$. Al margen de los títulos pertenecientes a las categorías de Religión ${ }^{49}$, Lengua y Literatura ${ }^{50}$,

41 Joannes Vaillant, Numismata Graeca, Amsterdam, 1700.

42 ID., Historia numismática Ptolemaeorum Aegypti regum, Amsterdam, 1701.

43 ID., Historia numismática Regum Syriae, La Haya, 1732.

44 Estas obras, a pesar de la descripción poco clarividente del inventario, ha sido identificadas gracias a lo contenido en John TOWNELEY, Biblioteca Towneleiana. A catalogue of the curious and extensive library of the late fohn Towneley, 2 t., Londres, 1814-1815, t. 1, p. 6.

45 Siendo esta la única publicación sobre pintura que se conserva en los inventarios de Antonio Caballero y Góngora. Iván de BUTRON, Discursos apologeticos en que se defiende la ingenuidad del arte de la pintura, Madrid, 1626.

46 Dichos libros fueron colocados junto a los aposentos del prelado en el Palacio Episcopal de Córdoba, concretamente «en la Galeria sobre la Puerta principal» del mismo, «para tenerlos a mano, cerrados, pero siempre a la vista». AGOC, Expolios, 9647, exp. 2, ff. 58v-59r.

47 Teniendo en cuenta lo contenido en Francisco AgUILAR PIÑAL, Bibliografía de autores españoles del siglo XVIII, 10 t., Madrid, 1981-2001, t. 10, p. 1775, es probable que se trate del título Real Ordenanza para el régimen y gobierno de la cría de caballos de raza en los Reynos de Andalucia, Murcia y Provincia de Extremadura, Madrid, 1775.

48 Constituciones de la Real y Distinguida Orden Española de Carlos Tercero, Madrid, 1771.

49 Véanse, por ejemplo, los títulos Benito ARIAS MonTANO, Biblia Sacra. Hebraice, Chaldaice, Grece, \& Latine, 8 t., Amberes, 1568-1572; Ioan MARQUEZ, El Gobernador Cbristiano, Madrid, 1625; Memorias sobre el exercicio discreto de la virtud de la Caridad en el repartimiento de la Limosna, Madrid, 1784; así como las Colecciones de Concilios del Padre Arduino, a las que se hacen referencia en Manuel VELEZ MARIN, Disertacion sobre las letanias antiguas de la Iglesia de España, Madrid, 1758, p. 115.

50 Entre otros figuran Luis de GÓNGORA, Obras, 3 t., Madrid, 1633; Francisco PÉREZ BAYER, Del alfabeto de los fenicios y de sus colonias, Madrid, 1772; Sor Ana de SAN GERÓNIMO, Obras poéticas, Córdoba, 1773; Fray Luis de GranaDA, Obras, 12 t., Pamplona, 1780; Jean de la FonTAINE, Fabulas Morales Escogidas, Madrid, 1787. 
Historia ${ }^{51}$ y Ciencia ${ }^{52}$, merece especial mención el hecho de que Caballero y Góngora transportó consigo las citadas 8 obras relacionadas con la Guerra, la Navegación y las Indias occidentales ${ }^{53}$, a pesar de trasladarse a España para ocupar un cargo ajeno a dichas disciplinas.

Finalmente, cabe destacar los títulos correspondientes a los apartados de $\mathrm{Nu}-$ mismática, Arquitectura e Ingeniería, especialmente relevantes por su significado y por aportar una mayor concreción sobre la cultura y las inquietudes de nuestro protagonista. Caballero y Góngora, particularmente preocupado por el conocimiento de la Historia a través del estudio de la Numismática, trajo consigo a Córdoba dos obras de Luis José Velázquez correspondientes a dicha materia ${ }^{54}$, otra del ya citado Jean Foy-Vaillant ${ }^{55}$, Museo de Medallas desconocidas españolas de Lastanosa ${ }^{56}$, la edición de Alla Sicilia Numismatica de Lancillotto ${ }^{57}$ y los tres tomos de Medallas de las Colonias, Municipios y pueblos antiguos de España de Enrique Flórez ${ }^{58}$. Obras que no sólo explican la mencionada predilección de Caballero y Góngora por la Numismática, sino también la amplia colección de monedas que poseía y que será tratada en otro apartado del presente artículo. Por otro lado, también merece ser mencionado el traslado a Córdoba de Le parfait Ingénieur Francois, ou La Fortification offensive et défensive de Deidier ${ }^{59}$ y los seis tomos de Cours d'architecture civile de Blondel ${ }^{60}$.

51 Concretamente, Martín de RoA, Antiguo Principado de Cordova En la España Ulterior o Andaluz, Córdoba, 1636; Pedro MEJÍA, Historia Imperial y Cesarea, Madrid, 1655; José Manuel TrelleS VILlademoros, Asturias ilustrada. Historia chronológica y genealógica del primitivo origen de la nobleza de España, su antigüedad, clases y diferencias, con sucessiones continuadas de las principales familias del Reyno, y con la ilustración del Principado de Asturias, 8 t., Madrid, 1760.

52 Francisco de Franco, Tratado de la Nieve y del uso della, Sevilla, 1569; Andrés FERNÁNDEZ, Instruccion de Enfermeros, Madrid, 1625.

53 Además de los no identificables «Diccionario de Batallas», «Ensayo de tactica», «Rios tactica» y «Cuadernos de los Sitios de Córdoba», véanse Nicolas MACHIAVELLI, Les Discours de l'Estat de Paix et de guerre, Madrid, 1579; Recopilacion de leyes de los reynos de las Indias, 9 t., Madrid, 1756; M. LE BLOND, Traité de l'attaque des places, Paris, 1762; Joseph Antonio PORTUGUES, Coleccion general de las Ordenanzas militares, 11 t., Madrid, 1764-1768.

54 Luis Joseph VeLAZQUEZ, Ensayo sobre los alfabetos de las Letras Desconocidas, Que se encuentran en las mas antiguas medallas, y Monumentos de España, Madrid, 1752; ID., Congeturas sobre las Medallas de los Reyes Godos y Suevos de España, Málaga, 1759.

55 Joannes VAILlANT, Numismata imperatorum romanorum praestantiora, a Iulio Caesare ad lostumum et tyrannos, Paris, 1674.

56 Vicencio Juan de Lastanosa, Museo de las medallas desconocidas españolas, Huesca, 1645.

57 Gabriele Lancillotto, Alla Sicilia Numismatica di Filippo Paruta, Palermo, 1770.

58 Henrique Florez, Medallas de las Colonias, Municipios y pueblos antiguos de España, 3 t., Madrid, 1757-1773.

59 DEIDIER, Le parfait Ingénieur Francois, ou La Fortification offensive et défensive, Amsterdam, 1734.

60 Jacques Francois BLONDEL, Cours d'architecture civile, 6 t., Paris, 1771-1777. 
La posesión de este último título, cedido por el prelado a la Escuela de Dibujo que él mismo proyectó en Córdoba para la formación de nuevos artistas ${ }^{61}$, adquiere una significación especial. Pues, a pesar de la notable influencia que su contenido ejerció sobre la Arquitectura española durante el último tercio del siglo XVIII, se han hallado pocos ejemplares del mismo en otras bibliotecas contemporáneas del ámbito hispánico ${ }^{62}$. Esta circunstancia evidencia nuevamente los recursos de Caballero y Góngora, su conocimiento de las tendencias más novedosas en las diferentes ramas del saber y sus inquietudes artísticas, apreciables también en su colección de obras de arte.

\section{OBRAS DE ARTE}

Durante los casi 22 años en los que ocupó la canonjía lectoral de la Catedral de Córdoba (1753-1775), Antonio Caballero y Góngora recopiló una notable colección artística ${ }^{63}$. Compuesta fundamentalmente por obras pictóricas, fue llevada (presumiblemente en su totalidad) a América en 1776 junto con el resto de sus posesiones. Tal y como ocurrió con su biblioteca, fue cedida parcialmente al Arzobispado de Santa Fé de Bogota antes de su regreso a España en 1789. Aunque gran parte del patrimonio artístico de nuestro protagonista ha sido publicado gracias a la existencia de dos inventarios fechados poco después de su llegada a América y justo antes de su vuelta a España, las incongruencias entre ambos documentos y algunas lagunas de los mismos no han permitido desvelar el destino de todas las obras de la colección. Sin embargo, la ya mencionada documentación hallada en el Obispado de Córdoba ha permitido esclarecer definitivamente el contenido de su colección artística, aclarar las obras que fueron traídas a España y desvelar ciertos datos que permitan establecer hipótesis sobre el paradero de algunas de ellas en investigaciones futuras.

61 Teniendo en cuenta tanto lo contenido en los inventarios que se están aportando, como en los de la citada Escuela de Dibujo, publicados en Juan ARANDA DONCEL, Un proyecto ilustrado en la Córdoba del siglo XVIII: La Escuela de Bellas Artes del obispo Caballero y Góngora, en Aphoteca, 6 (1986), pp. 33-49.

62 La propia Real Academia de Bellas Artes de San Fernando de Madrid, organismo encargado de la formación de los artistas y de la difusión de los valores estéticos de la Ilustración en España, no disponía de la totalidad de los tomos de este tratado en 1794. Una circunstancia que fue advertida por los miembros de dicha Academia en ARABASF, Biblioteca, Adquisiciones, 1-24-1, s/f.

63 Antonio PonZ, Viage de España, 18 t., Madrid, 1772-1794, t. 17, p. 39. 
Cotejando el contenido de los dos inventarios firmados por Antonio Velasco Ramírez ${ }^{64}$ el 15 de enero de 1789 en Bogotá ${ }^{65}$ y el 8 de abril en Cartagena de Indias $^{66}$, así como teniendo en cuenta lo expuesto en la relación de obras de arte fechada en $1777^{67}$, es posible establecer una lista de aquellas dejadas en Nueva Granada. Concretamente, las obras donadas al Arzobispado de Santa Fé de Bogotá, que en su mayoría debieron desaparecer en el incendio que sufrió su sede el 9 de abril de $1948^{68}$, corresponden con las siguientes representaciones pictóricas: un San José, que en todos los inventarios aparece como obra de Murillo; una Asunción de la Virgen; una negación de San Pedro, considerada como obra de «Il Guercino» en los tres inventarios; una serie de paisajes representativos de la vida de Jacob, que los dos documentos fechados en 1789 señalan como originales de Francisco Antolínez ${ }^{69}$; un niño Jesús dormido (probablemente sobre la cruz ${ }^{70}$ ), mencionada como obra de Alonso Cano salvo en el último de los inventarios; un bodegón reconocido unánimemente como obra de Peter Paul Rubens; un San Sebastián anónimo de pequeño formato; una vista de un palacio con un centro de frutas atribuido a Juan de Arellano; un crucificado de pequeñas dimensiones; y una serie de floreros en mal estado. Además de las obras citadas, el inventario redactado el 15 de enero de 1789 en Bogotá hace referencia a que Antonio Caballero y Góngora también dejó en la capital neogranadina un San Matías y un San Antonio Abad, reconocidos como obras de Luis de Morales; un San Miguel relacionado con la producción de Pablo de Céspedes; y un San Mateo de Tiziano ${ }^{71}$.

64 Quien estuvo al servicio de Antonio Caballero y Góngora durante 30 años según su propio testimonio. AGOC, Expolios, 9647, exp. 2, ff. 56r-58r.

$65 \mathrm{Al}$ que se anexionó otro documento firmado el día 26 del citado mes en Turbaco donde se añadían ciertos enseres a la lista de objetos que debían quedar en Bogotá. José Manuel PÉREZ AYALA, Antonio Caballero... [ver n. 2], pp. 189-193.

66 AGOC, Expolios, 9647, exp. 2, ff. 27r-27v.

67 Inventario solicitado por el propio Caballero y Góngora en 1777 a la Audiencia de México para evitar confusiones con las obras de arte ya pertenecientes al Obispado de Mérida. Véase Ernesto RESTREPO TIRADO, La fortuna del excelentísimo señor don Antonio Caballero y Góngora, en Boletín de Historia y Antigüedades, 177 (1926), pp. 567-571.

68 Sobre el mismo y sus circunstancias véase Camilo VILLATE y Brando TAMAYO, Torre de oficinas Avianca, Bogotá, 2012, p. 43.

69 Bien podrían estar relacionadas con las obras realizadas por Antolínez y correspondientes a la misma temática ubicadas actualmente en el Museo de Bellas Artes de Sevilla y en el Museo Cerralbo de Madrid. Véase al respecto lo contenido en Diego ANGULO ÍÑIGUEZ, Murillo y su escuela en colecciones particulares, Sevilla, 1975, pp. 29-33.

70 Acerca de esta iconografía y su presencia en el siglo XVII andaluz, sobre todo en la producción de Murillo, véase Nerea Virginia PÉREz LÓPEZ, Murillo y los orígenes de la iconografía del Niño fesús dormido sobre la cruz, en Boletín de Arte, 36 (2015), pp. 145-154.

71 José Manuel Pérez AYala, Antonio Caballero... [ver n. 2], pp. 189-193. 
Por otro lado, el inventario firmado el 8 de abril de 1789 en Cartagena de Indias no sólo se refiere a las obras dejadas en Nueva Granada, como ocurre en el caso del fechado el 15 de enero, sino que aporta una lista de las obras de arte que Caballero y Góngora llevó a Córdoba. En concreto, dicho documento se refiere a una lámina de bronce de origen italiano, iconográficamente correspondiente con el Descendimiento de Cristo $^{72}$; una Resurrección de Cristo original de Antonio del Castillo que ocupaba el altar mayor del oratorio del Palacio arzobispal de Bogotá, en cuyo lugar se colocó la pintura de San José antes mencionada; un San Pedro de Alcántara, obra de Luca Giordano; dos pinturas (una ovalada y otra rectangular) que representaban a San Pedro; una Presentación de la Virgen; un retrato del Papa Pío VI ${ }^{73}$; y un retrato ovalado del propio Caballero y Góngora ${ }^{74}$.

En mayo de 1796, tras la defunción del prelado cordobés, se redactó un nuevo inventario sobre las obras pictóricas que le pertenecían, ubicadas entonces en el domicilio de su «Pintor de Cámara», Francisco Agustín ${ }^{75}$. Este inventario aporta nuevos datos sobre las obras contenidas en el listado del 8 de abril de 1789 y hace referencia a otras pinturas llevadas a Córdoba no reseñadas en el mismo $^{76}$. Siguiendo el orden de la lista antes descrita, así como señalando la más que posible inexactitud de las medidas indicadas, el inventario de 1796 expone que la Resurrección de Cristo de Antonio del Castillo medía una vara $(83 \mathrm{~cm})$ de alto; el San Pedro de Alcántara de Luca Giordano (en mal estado) se encontraba adorando la cruz, siendo sus medidas tres cuartas $(63 \mathrm{~cm})$ de alto y «poco menos de ancho»; la pintura ovalada de San Pedro representaba al mismo en «acto penitente», a la vez que, en vez de catalogarla como ovalada, hace referencia a ella como un «imperfecto círculo» de «menos de una vara» (entre 60 y $80 \mathrm{~cm}$ ) de diámetro; la otra pintura de San Pedro medía cinco cuartas $(104 \mathrm{~cm})$ de alto

72 Y que, presumiblemente, Caballero y Góngora iba a colocar en el retablo que debía presidir la capilla del oratorio privado del Palacio episcopal de Córdoba, el cual fue diseñado por su «Arquitecto de Cámara» Ignacio Tomás. ARABASF, Secretario General, Académicos, Comunicaciones de fallecimientos y notas necrológicas, 1-47-2, Antonio Caballero y Góngora, f. 13v.

73 De dos varas y cuarta de alto y vara y media de ancho, con un marco dorado proveniente de Roma. AGOC, Expolios, 9646, exp. 4, f. 179r.

74 AGOC, Expolios, 9647, exp. 2, ff. 27r-27v.

75 AGOC, Expolios, 9647, exp. 2, ff. 42r-43r.

76 Pinturas que, según el testimonio de Miguel Toledano y Alfonso (presbítero, familiar directo y colaborador de Caballero y Góngora), fueron donadas parcialmente al Rey una vez se inventariaron los bienes del prelado difunto. ARABASF, Secretario General, Académicos, Comunicaciones de fallecimientos y notas necrológicas, 1-47-2, Antonio Caballero y Góngora, f. 12r. 
y una vara $(83 \mathrm{~cm})$ de ancho ${ }^{77}$; la Presentación de la Virgen alcanzaba «más de dos varas» (entre 170 y $200 \mathrm{~cm}$ ) de alto y «más de una vara y media» (entre 130 y $150 \mathrm{~cm}$ ) de ancho ${ }^{78}$; y el retrato ovalado de Caballero y Góngora medía una vara $(83 \mathrm{~cm})$ de diámetro ${ }^{79}$.

Además de los detalles expuestos sobre las obras ya enunciadas en el inventario del 8 de abril de 1789, el de 1796 añade varias obras más a la lista de pinturas traídas por Caballero y Góngora a Córdoba. Concretamente, hace referencia a una Inmaculada Concepción tenida como obra de Murillo ${ }^{80}$, de una vara $(83 \mathrm{~cm})$ de alto $^{81}$; dos «ovalitos» de Antonio del Castillo que representaban el «Nacimiento» de Cristo y el «Anuncio de los pastores» ${ }^{82}$, de media vara $(42 \mathrm{~cm})$ de diámetro «por lo más alto»; una «media figura» de la Virgen del Rosario copiada de Murillo, también ovalada y de una vara $(83 \mathrm{~cm})$ de diámetro; dos cabezas de San Antonio Abad y San Pablo como primeros ermitaños consideradas obras originales de Murillo, de «más de tres cuartas» (70 $\mathrm{cm}$ aproximadamente) de alto y de ancho; cuatro fruteros «compañeros» de «más de una tercia» $30 \mathrm{~cm}$ aproximadamente) de alto y dos cuartas y media $(52 \mathrm{~cm})$ de ancho; una representación de

77 Según consta en el inventario de 1777, la primera de las representaciones de San Pedro era considerada obra de Francisco Herrera el Viejo y la segunda de ellas obra de José de Ribera. Ernesto Restrepo Tirado, La fortuna... [ver n. 67], p. 569. La autoría de Herrera el Viejo aparece también mencionada posteriormente en AGOC, Expolios, 9646, exp. 4, f. 178r.

78 Obra que Pérez Ayala y Restrepo Tirado consideraban que había sido realizada por Juan Carreño de Miranda (José Manuel PÉrEZ Ayala, Antonio Caballero... [ver n. 2], pp. 189-190). No obstante, bien podría estar relacionada con la pintura española de la segunda mitad del siglo XVII en general, dadas las incertidumbres que generan las atribuciones que están siendo expuestas. Véase la obra de dicho periodo, de la misma iconografía y de similares proporciones llevada a cabo por el granadino Juan de Sevilla Romero y Escalante, ubicada actualmente en el Museo del Prado y proveniente de las colecciones reales.

79 AGOC, Expolios, 9647, exp. 2, ff. 42r-43r.

80 Concretamente se trata de «un borron», por lo que estamos ante un boceto o un pensamiento. AGOC, Expolios, 9646, exp. 4, f. 178r.

81 Si bien se ha escrito mucho en diferentes publicaciones sobre obras concretas inspiradas, copiadas o modificadas de la producción de Murillo y sus autores, véase en este sentido, entre otros, lo contenido en Alfredo J. MoRALES, Murillo restaurador y Murillo restaurado, en Archivo Español de Arte, 240 (1987), pp. 475-480; María de los Santos García Felguera, La fortuna de Murillo (1682-1900), Sevilla, 1989. Sobre el coleccionismo de obras pictóricas andaluzas en general y de Murillo en particular durante los siglos XVII y XVIII consúltese Alfredo UREÑA UCEDA, La pintura andaluza en el coleccionismo de los siglos XVII y XVIII, en Cuadernos de Arte e Iconografía, 13 (1998), pp. 99-148.

82 Cuyas medidas y forma coinciden con «El Sueño de San José» y el «Sacrificio de Isaac» del propio Castillo, ubicados en el Museo de Bellas Artes de Córdoba. Véase al respecto Benito NAVARRETE PRIETO y Fuensanta GARCÍA DE LA TORRE, Antonio del Castillo en la senda del Naturalismo, Córdoba, 2016, pp. 184-185. 
Lot y sus hijas de «menos de una vara» (entre 70 y $80 \mathrm{~cm}$ ) de alto y cinco cuartas $(104 \mathrm{~cm})$ de ancho $^{83}$; un crucificado tenido por obra de Alonso Cano de «más de una vara» (entre 85 y $100 \mathrm{~cm}$ ) de alto y ancho; una pintura en la que se muestra a San Francisco «asistido por el Padre Eterno y Ángeles» vinculada a la producción de Luca Giordano ${ }^{84}$, de tres cuartas $(63 \mathrm{~cm})$ de alto y media vara $(42 \mathrm{~cm})$ de ancho; una representación de Eliezer y Rebeca sacando agua del pozo, de Francisco Solimena, de media vara $(42 \mathrm{~cm})$ de alto y una tercia $(27 \mathrm{~cm})$ de ancho; otro en el que se escenifica el pasaje de la curación de Tobias, en mal estado y de alrededor de una vara $(83 \mathrm{~cm})$ de alto y cinco cuartas $(104 \mathrm{~cm})$ de $a n c h o^{85}$; una lámina «pequeña» donde se representa a la Virgen del Mayor Dolor, «con un marco con follajes y embutidos de borlas y apreciables maderas y algunos bronces»; una lámina «apaisada» que representa la Crucifixión siguiendo un modelo de Rubens, la cual acababa de ser dorada; una «efigie» de una dolorosa copia de un original de Guido Reni existente en Roma, de tres cuartas $(63 \mathrm{~cm})$ de alto y ancho; y un «piojoso» tenido como original de Murillo ${ }^{86}$ de cinco cuartas $(104 \mathrm{~cm})$ de alto y tres y media $(73 \mathrm{~cm})$ de ancho ${ }^{87}$.

Asimismo, en el «General inventario de los bienes y efectos del Palacio Episcopal», fechado el 18 y 19 de mayo de 1796, las pinturas traídas a Córdoba fueron tasadas por los «Pintores de Cámara» Francisco Agustín y Antonio Monrroy, quienes también hicieron referencia a una serie de obras de arte pertenecientes a Caballero y Góngora no mencionadas con anterioridad ${ }^{88}$. De este modo, completaban la colección artística del difunto prelado un lienzo de

83 Relacionada con la producción de Guido Reni en el inventario de 1777 (Ernesto RESTREPO TIRADO, La fortuna... [ver n. 67], p. 568), puede que se trate de alguna de las numerosas copias basadas en la pintura que sobre esta iconografía realizó el citado artista italiano.

84 También conocido como «La humildad triunfante de San Francisco». AGOC, Expolios, 9646, exp. 4, f. $171 \mathrm{v}$.

85 Teniendo en cuenta que esta pintura era considerada como obra de Guido Reni o de un maestro italiano de la primera mitad del siglo XVII, así como reparando en sus medidas, bien podría relacionarse con la «Curación de Tobías», copia de Bernardo Cavallino, que existe actualmente en el Museo del Prado. Alfonso Emilio PÉREZ SÁNCHEZ, Pintura italiana del siglo XVII en España, Madrid, 1965, p. 462.

86 Cabe destacar que en un documento firmado el 8 de mayo de 1794, referente a los motivos por los que pedía la admisión del escultor José Álvarez Cubero en la Real Academia de Bellas Artes de San Fernando, el propio Caballero y Góngora hacía referencia a los muchos originales de Murillo que había en la ciudad de Córdoba. Obras que se fueron extraviando durante las últimas décadas del siglo XVIII por la declinación del «gusto de los aficionados». ARABASF, Secretario General, Enseñanza, Pensionados, 1-48-1, José Álvarez, s/f.

87 AGOC, Expolios, 9647, exp. 2, ff. 42r-43r.

88 AGOC, Expolios, 9646, exp. 4, ff. 170r-180r. 
dos varas $(168 \mathrm{~cm})$ de alto y cinco tercias $(138 \mathrm{~cm})$ de ancho que contenía doce escenas de la Pasión, atribuido «sin duda a algún celebre veneciano de la escuela de Tiziano»; una Adoración de los Reyes «original de Antonio del Castillo», de siete cuartas $(146 \mathrm{~cm})$ de alto y cuatro tercias $(110 \mathrm{~cm})$ de ancho; dos vistas del Vesubio y del Etna «pintadas sobre papel y puestas en marcos de color Lapislázuli y moldura dorada», de una tercia $(27 \mathrm{~cm})$ de alto y media vara $(42 \mathrm{~m})$ de ancho; una Santa Catalina Mártir «original de la Escuela de Céspedes», de una vara y media $(125 \mathrm{~cm})$ de alto y una vara $(83 \mathrm{~cm})$ de ancho; seis «Perspectivas de Arquitectura» de cinco cuartas $(104 \mathrm{~cm})$ de alto y una vara $(83 \mathrm{~cm})$ de ancho; «Otras seis perspectivas» representativas de las obras de Misericordia, del mismo tamaño; una medalla de bronce dorado que representaba a Cristo muerto en brazos de la Virgen acompañada de Ángeles, con una orla del mismo material en la que aparecían los atributos de la Pasión de Cristo; un «cuadrito de escayola» de media vara de alto $(42 \mathrm{~cm})$ y una tercia $(27 \mathrm{~cm})$ de ancho en el que se representaba a Santa Ana dando lección a la Virgen; tres «pensamientos de originales de Palomino ejecutados de claro y oscuro», correspondientes a los tres lienzos de la Capilla del Cardenal Salazar de la Catedral de Córdoba ${ }^{89}$, de tres cuartas y media $(73 \mathrm{~cm})$ de alto y media vara $(42 \mathrm{~cm})$ de ancho; cinco fruteros circulares, «todos iguales», de una tercia $(27 \mathrm{~cm})$ de diámetro y pintados sobre tabla; dos estampas con sus marcos azules dorados, de tres cuartas $(63 \mathrm{~cm})$ de alto y media vara $(42 \mathrm{~cm})$ de ancho, que figuraban a la Sagrada Familia y a San Antonio de Padua; una lámina de cobre apaisada con la representación del «Estado Militar» y de las «Armas Reales», de dos tercias de alto $(55 \mathrm{~cm})$ y tres cuartas $(63 \mathrm{~cm})$ de ancho; un crucifijo de «bronce pintado» con cruz de madera y adornos dorados, de una vara $(83 \mathrm{~cm})$ de alto; seis estampas que contenían «diseños de la Catedral de Málaga»; dos retratos de «los monarcas españoles», de «medio cuerpo»; un dibujo alegórico del propio Antonio Caballero y Góngora ejecutado por Miguel Verdiguier ${ }^{90}$; dos pequeñas láminas que representaban a San Pelagio y a «una mujer»; y una escultura de un Ángel de la Guarda, de una vara $(83 \mathrm{~cm})$ de alto ${ }^{91}$.

Todas las obras citadas, salvo el «piojoso de Murillo» (propiedad del Obispado de Córdoba), fueron confirmadas como pertenecientes a Antonio Caballero y Góngora por Antonio Velasco Ramírez y Miguel Jerónimo Collado en sendos

89 Sobre dichas pinturas véase lo referido en Manuel Nieto CumPlido, La Catedral de Córdoba, Córdoba, 1998, pp. 370-373.

90 A quien Antonio Caballero y Góngora pensionó pagando los gastos del arrendamiento de su vivienda entre 1794 y 1796. AGOC, Expolios, 9645, exp. 4, s/f.

91 AGOC, Expolios, 9646, exp. 4, ff. 170r-180r. 
testimonios ${ }^{92}$. Se trata, como puede comprobarse, de una notable colección artística que evidencia el reconocido interés de Caballero y Góngora por el arte y cuyo contenido está relacionado con el de otros conjuntos contemporáneos ${ }^{93}$. En resumen, la colección estaba conformada mayoritariamente por obras españolas de los siglos XVII y XVIII, así como también por otras tantas ejecutadas en Italia durante dichas centurias, algunas de diversa procedencia creídas como del siglo XVI y ciertos casos concretos de origen flamenco. Un conjunto de obras artísticas que fue adquirido mayoritariamente durante el periodo en el que ocupó la canonjía lectoral de Córdoba, llevadas a América en 1776 y traídas parcialmente de regreso a España en 1789 junto a una serie de objetos valiosos de diferente índole recopilados antes o durante su estancia al otro lado del Atlántico.

\section{OBJETOS LITÚRGICOS, CIENTÍFICOS Y AMERICANISTAS}

$\mathrm{Al}$ igual que otras destacadas personalidades españolas de la segunda mitad del siglo XVIII ${ }^{94}$, Caballero y Góngora reunió (fundamentalmente durante su estancia en América) un conjunto de piezas de singular valor, ya fuera por su riqueza material, su significado o su origen americano indígena ${ }^{95}$. Concretamente, el listado de piezas preciadas traídas a España por nuestro protagonista estaba compuesto, al margen de alhajas ${ }^{96}$, por todo tipo de objetos preciosos destinados al uso personal, institucional y litúrgico; instrumentos empleados con fines científicos; materiales autóctonos del Virreinato neogranadino; objetos devociona-

92 Ambos testimonios están fechados el 4 de marzo de 1797. AGOC, Expolios, 9647, exp. 2, ff. 56r-60v.

$93 \mathrm{Al}$ respecto véase Diana URRIAGLi SERRANO, Coleccionismo de Pintura en España en la segunda mitad del siglo XVIII, en Luis SAZATORNIL RUIZ y Frédéric JIMÉNO (eds.), El arte español entre Roma y París (siglos XVIII y XIX), Madrid, 2014, pp. 239-256. Sobre algunas colecciones de pintura concretas, pertenecientes a contemporáneos de Caballero y Góngora, consúltese Isadora Joan Rose Wagner, Manuel Godoy Patrón de las Artes y Coleccionista, Madrid, 1983; Javier Jordán de URRÍES Y DE LA COCINA, El coleccionismo del ilustrado Bernardo Iriarte, en Goya, 319-320 (2007), pp. 259-280; Ignacio GIL-DíEZ UsandiZAGa, Sebastián Martínez, el amigo de Goya, en Brocar, 18 (2014), pp. 197-209; Elena María Santiago PáEZ (dir.), Ceán Bermudez. Historiador del arte y coleccionista ilustrado, Madrid, 2016.

94 Sobre este asunto consúltese María Paz CABEllo CARro, Coleccionismo americano indígena en la España del siglo XVIII, Madrid, 1989.

95 En este sentido conviene destacar lo referido en María Paz CABEllo CARro, La formación de las colecciones americanas en España. Evolución de los criterios, en Anales del Museo de América, 9 (2001), pp. 303-318.

96 Entre ellas una «bateria de hoja de plata noble a estrenar inglesa» y todo tipo de ropajes de carácter litúrgico. AGOC, Expolios, 9647, exp. 2, ff. 28r-33r, 44r-45v, 48r-50r. 
les; algunos elementos identificativos de la tradición cultural americana; y otros pertenecientes a las tribus indígenas aún existentes en el continente. Y es que, Caballero y Góngora no sólo se mostró como un individuo preocupado por la erudición, las artes o el coleccionismo exótico ${ }^{97}$, sino que también se interesó por el estudio social y antropológico de los pueblos indígenas que habitaban Nueva Granada. Por todo ello, el amplio conjunto de bienes preciados traídos de América por el prelado cordobés alcanzó una riqueza, una diversidad y un significado que, mediante la exposición de los casos más representativos, pretenden ser desvelados a continuación.

El primer grupo de esta sección estaba conformado por objetos de carácter devocional y litúrgico de diversa naturaleza, composición y procedencia, siendo la gran mayoría de ellos adquiridos durante la etapa americana de Caballero y Góngora. Por un lado, constan dispares piezas (báculos, cruces o libros sagrados) de plata labrada, oro y carey ${ }^{98}$; y una decena de cálices compuestos por diferentes materiales (por ejemplo, de algodón tejido con remates de oro o de madera de choco combinada con plata) en cada uno de los casos. Por otro, el inventario menciona la existencia de varios objetos devocionales, como una imagen de la Virgen del Carmen dentro de una caracola, un crucifijo de filigrana de oro esmaltado, un relicario de oro, varias medallas de plata con diferentes advocaciones religiosas o, incluso, «cintas tocadas por la Virgen de Chiquinquirá» ${ }^{99}$.

El segundo y más numeroso grupo de los que nos ocupan estaba compuesto por objetos de toda índole destinados al uso privado del prelado. Destacan entre todos ellos por su valor material varios peines, cuchillos y bastones de carey y marfil, materiales muy preciados y habituales en los inventarios de bienes de la nobleza y el alto clero español en América ${ }^{100}$. Asimismo, la lista expone la posesión de determinados continentes singulares, tales como «cajas de concha de Panamá»; varias sortijas con topacios y amatistas; cristales de roca de las

97 El papel de los objetos de origen americanista y el germen de la significación intelectual de los mismos en las colecciones europeas viene reflejado en Isabel YAYA, Wonders of America: The curiosity cabinet as a site of representation and knowledge, en Fournal of the History of Collections, 20 (2008), pp. $173-188$.

98 Materiales característicos de ajuares tanto domésticos, como litúrgicos de la época. Véase al respecto el caso expuesto en Javier NADAL INIESTA, El mobiliario doméstico en la Murcia de principios del siglo XVIII (1700-1725), en Imafronte, 18 (2016), pp. 93-103.

99 AGOC, Expolios, 9647, exp. 2, ff. 28r-33r.

${ }^{100}$ Véase al respecto lo referido en Francisco MONTES GONZÁLEZ, Una aproximación a las fuentes documentales para el estudio del coleccionismo americano en España, en Artigrama, 24 (2009), pp. 205 223. 
minas de Mariquita ${ }^{101}$; un gran número de cadenas y medallas de oro de diversa índole; y seis relojes de sobremesa ricamente decorados. Lista de objetos valiosos de uso personal al que habría que sumar también todo el mobiliario, el ajuar textil, grandes cantidades de materiales consumibles como el tabaco o la tinta, el amplio número de medicinas y bálsamos traídos de América ${ }^{102} \mathrm{o}$ varios tipos de anteojos ${ }^{103}$.

De significativa importancia para conocer el perfil del personaje cuya colección está siendo reflejada son algunos objetos vinculados al estudio de la ciencia, tales como una cámara oscura para la visualización invertida de los objetos, una bola concéntrica, piedras «correspondientes a la Historia Natural» con sus correspondientes memoriales, un grafómetro para la medición de ángulos y una cuerda de hierro para medir terreno. Teniendo en cuenta las inquietudes científicas de Caballero y Góngora antes mencionadas en la exposición de su biblioteca, estos instrumentos debieron servir para el estudio práctico de las diferentes ramas del conocimiento durante el último periodo de su vida. El cual no solo se desarrolló en el Palacio Episcopal de Córdoba, sino también en dos fincas cercanas a la localidad cordobesa cedidas por el Duque de Alba y el Marqués de Guadalcazar ${ }^{104}$, donde tuvo mayor espacio y tiempo para utilizar dichos instrumentos y cotejar su uso con la información contenida en los títulos que conformaban su biblioteca.

Mención aparte merece el sustancioso acopio de maderas autóctonas que llevó a cabo Caballero y Góngora durante su estancia en América. Concretamente, el prelado recopiló un total de 347 piezas lignarias ${ }^{105}$ de diferentes especies (caoba, manzanillo, gateado, cocobolo, palo de rosa y palo nazareno ${ }^{106}$ ) que fueron utilizadas en parte para la ejecución del mobiliario de la Escuela de Dibujo que Caballero y Góngora proyectó en el Palacio Episcopal de Córdoba a partir de $1790^{107}$. Además, trajo a la ciudad cordobesa piezas de Guayacán (palo san-

${ }^{101}$ Sobre las mismas consúltese Heraclio BonILla, Las minas de Mariquita en el Nuevo Reino de Granada: Minería, mano de obra y circulación monetaria en los Andes del siglo XVII, Madrid, 2015.

102 Véase el listado completo de los mismos en AGOC, Expolios, 9648, exp. 9, s/f.

103 AGOC, Expolios, 9647, exp. 2, ff. 28r-33r.

104 Concretamente se trata de la «Villa del Montón de Tierra» y la «Hacienda de Alisne» respectivamente. AGOC, Expolios, 9646, exp. 1, s/f.

${ }^{105} \mathrm{El}$ listado completo de las mismas aparece reflejado en AGOC, Expolios, 9647, exp. 2, ff. 46r-47r.

106 AGOC, Expolios, 9646, exp. 4, ff. 222r-252r.

107 Según el testimonio contenido en ARABASF, Secretario General, Académicos, Comunicaciones de fallecimientos y notas necrológicas, 1-47-2, Antonio Caballero y Góngora, f. 13r. Véase el inventario de la citada Escuela de Dibujo en Juan ARANDA DONCEL, Un proyecto... [ver n. 61], pp. 33 49. 
to) destinadas a la confección de enseres personales, del mismo modo que llevó consigo un «corazón» petrificado de dicha especie. Y es que, al margen de la utilidad que pudiera darle a las maderas mencionadas, esta recopilación certifica el interés por el estudio de la Flora neogranadina de Caballero y Góngora, más aún teniendo en cuenta que fue poseedor de libros vinculados con dicha materia y el promotor de la Expedición Botánica de Nueva Granada, fundada en 1783 y dirigida por José Celestino Mutis ${ }^{108}$.

Los últimos y, probablemente, más singulares objetos de este apartado y de toda la colección de Caballero y Góngora son aquellos de carácter antropológico y natural vinculados a la Cultura de las tribus indígenas del territorio neogranadino. Por un lado, trajo varios plumeros pertenecientes a diferentes aves americanas, siguiendo así la tendencia del coleccionismo americanista durante la Edad Moderna, que, desde el siglo XVI otorgó una gran importancia a este tipo de objetos $^{109}$. Pero, sobre todo, destaca la pertenencia de decenas de frutos de bixas de orellana del Darién ${ }^{110}$ «sacadas por los indios para pintarse» ${ }^{111}$, que Caballero y Góngora debió obtener durante su estancia en Turbaco, mientras dirigía las campañas militares para la reducción de las conflictivas tribus cunas ${ }^{112}$. Objetos que, ya fuera por la necesidad de estudiar la Cultura de dichas tribus durante las campañas militares referidas o como trofeo de las mismas (teniendo presente su citado interés por la Flora), retratan a Caballero y Góngora no sólo como un coleccionista habitual de objetos exóticos o valiosos de procedencia americana ${ }^{113}$, sino también como un personaje interesado por la Antropología.

108 Véase al respecto Jose Celestino MUTIS, Diario de observaciones de Fosé Celestino Mutis (17601790), Bogotá, 1957; Jose Antonio AMAYA, Bibliografía de la Real Expedición Botánica del Nuevo Reino de Granada, Bogotá, 1983.

109 Téngase en cuenta lo referido en Alessandra Russo, El encuentro de dos mundos artísticos en el arte plumerío mexicano del siglo XVI, en Probistoria: Historia, políticas de la Historia, 2 (1998), pp. 63-91; Friederike BERLEKAMP, Acerca de la investigación del arte plumario colonial de Sudamérica. Posibilidades y perspectivas de la Cultura visual histórica en un contexto intercultural, en Diálogo Andino, 49 (2016), pp. 113-122.

${ }^{110}$ El uso del pigmento derivado de esta planta por parte de los indios del Darién viene reflejado en Jorge MORALES GÓMEZ, Notas etnográficas sobre la tecnología de los indios cuna, en Revista Colombiana de Antropopología, 19 (1975), pp. 79-102.

111 AGOC, Expolios, 9647, exp. 2, ff. 28r-33r.

112 Sobre dichas campañas consúltese Nelson Eduardo RoDRÍGUEZ, El imperio... [ver n. 9], pp. 201223.

113 Relacionable con el caso, nuevamente paralelo, de Francisco Lorenzana. Paula REvENGA DoMÍNGUEZ, El coleccionismo ilustrado del cardenal Lorenzana entre España y México, en Oscar FlORES FlORES (coord.), El Clasicismo en la época de Pedro fosé Márquez (1741-1820), México, 2014, pp. 205-221. 
UN COMPENDIO PARA EL ESTUDIO DE LA HISTORIA: LA COLECCIÓN DE NUMISMÁTICA

A lo largo del siglo XVIII, el fomento del conocimiento histórico alcanzó una especial significación como parte del progreso intelectual promovido por el movimiento cultural ilustrado ${ }^{114}$. En este sentido, la numismática alcanzó una importancia capital para el estudio de la Historia, dadas las posibilidades que ofrecía como fuente primaria para ahondar, fundamentalmente, en la investigación de los periodos de dominación romana y visigoda de la Península Ibérica. Entre ellos destacó Caballero y Góngora, quien, como ya se ha podido comprobar en el apartado dedicado a su biblioteca, profundizó en la investigación histórica a través de la Numismática, ya que era poseedor de una de las colecciones privadas de monedas antiguas más importantes de España.

Se trata de un compendio numismático recopilado en su gran mayoría durante el periodo que ocupó la canonjía lectoral de la Catedral de Córdoba y que, a su llegada a América, estaba conformado por 504 monedas romanas de plata republicanas; 2 imperiales de oro, 447 de plata y 2.624 de bronce; 16 con símbolos de deidades romanas; 215 de oro y plata de diferentes familias patricias romanas; 34 provenientes de la Península Ibérica anteriores a la conquista romana; 11 de oro correspondientes al periodo de dominación visigoda y varias más de plata; 11 de oro, 200 de plata y 1.252 de diferentes materiales, medievales y representativas de los papas y los reyes de Castilla; 12 de oro, 252 de plata y 264 de bronce procedentes del ámbito islámico medieval; 526 de varias «poblaciones españolas»; y 69 camafeos de diferentes épocas ${ }^{115}$. Un compendio de alrededor de 6.500 piezas a las que, incluso, Caballero y Góngora sumó otras tantas durante su estancia en América, hasta casi alcanzar las 7.000 unidades ${ }^{116}$ y componer cuantitativamente una de las colecciones de este género más importantes de cuantas se conocen en el ámbito hispánico.

No obstante, a pesar de su importancia numérica y cualitativa, la colección numismática de Caballero y Góngora destacó sobre todo como instrumento para la investigación histórica, dado que fue consultada por los especialistas en la materia y reproducida para su estudio por parte de los mismos. Como ejemplo de

114 Isabel RODRÍGUEZ CASANOVA, La numismática en la España de la Ilustración, en Martín ALMAGRO GORBEA y Jorge MAIER Allende (coords.), De Pompeya al Nuevo Mundo. La corona española y la arqueología en el siglo XVIII, Madrid, 2012, pp. 157-172.

115 Ernesto RESTREPO TIRADO, La fortuna... [ver n. 67], p. 570.

116 AGOC, Expolios, 9647, exp. 2, f. 30v. 
ello cabe destacar que el afamado historiador agustino Enrique Flórez ${ }^{117}$, uno de los eruditos más relevantes del siglo XVIII español, visitó Córdoba en 1766 para conocer la colección de monedas de nuestro protagonista (por entonces canónigo lectoral de la Catedral de Córdoba), de cuyos ejemplares obtuvo diferentes copias $^{118}$. Flórez, quien ilustró y comentó una de las monedas visigóticas más singulares de la colección de Caballero y Góngora en el tercer tomo de su tratado sobre la numismática española ${ }^{119}$, no fue el único contacto del (todavía) canónigo cordobés, pues éste formaba parte de un grupo concreto de coleccionistas y estudiosos de la disciplina que se comunicaban sus nuevas adquisiciones y avances mediante correspondencia regular. Ejemplo de ello son las misivas intercambiadas entre Caballero y Góngora y Fernando José de Velasco y Ceballos ${ }^{120}$ en 1764, por las cuales el canónigo cordobés informaba a ese último de las nuevas adquisiciones del apartado de numismática de su «museo» (sobre todo en lo que respecta a monedas visigóticas), de la cantidad de monedas antiguas existentes en Córdoba y de la importante colección que también poseía el chantre de su Catedral, Juan Antonio Carrascal, con quien estaba en permanente contacto ${ }^{121}$. Asimismo, también existe constancia de la correspondencia mantenida entre Caballero y Góngora, Pedro Leonardo de Villacevallos ${ }^{122}$ y el ya mencionado Enrique Flórez, quien remarcó en 1771 la calidad de la colección del canónigo cordobés, sobre todo por la rareza y valor de las monedas visigóticas que la integraban ${ }^{123}$, las más ambicionadas por los coleccionistas españoles. Estos contactos constatan no sólo el periodo en el que Caballero y Góngora contaba ya con la mayor parte de su

117 Sobre el mismo y su trabajo como historiador véase F. Javier CAMPOS Y FERNÁNDEZ DE SEVILLA, El P. Flórez y los estudios de la Historia Antigua de España en el reinado de Carlos III (1759-1788), en Cuadernos de Investigación Histórica, 27 (2010), pp. 23-63.

118 ARABASF, Secretario General, Académicos, Comunicaciones de fallecimientos y notas necrológicas, 1-47-2, Antonio Caballero y Góngora, f. 14r.

119 Henrique FloreZ, Medallas de las colonias... [ver n. 58], t. 3, p. 279.

120 Sobre la importancia de este coleccionista y erudito como uno de los más destacados de Andalucía durante el siglo XVIII véase Jesús SALAS ÁLVAREZ, El coleccionismo numismático en Andalucía durante la Ilustración, en Nvmisma, 252 (2008), pp. 149-176.

${ }^{121}$ Fernando José de VelasCo y CEBALlos, Documentos y correspondencia sobre numismática. BNE, Mss/2537, ff. 31r-34r.

122 Quien contaba con una colección de 2.343 monedas antiguas, según lo contenido en Bartolomé Mora SerRano, Las monedas, en José Beltrán ForTeS y José Ramón LópeZ RodrígueZ (coords.), El museo cordobés de Pedro Leonardo de Villacevallos, Madrid, 2003, pp. 219-322.

123 F. Javier CAMPOS Y FERNÁNDEZ DE SEVILLA, Epistolario ilustrado: La correspondencia del Agustino P. Enrique Flórez con D. Pedro Leonardo de Villacevallos (1744 a 1759), y D. Antonio Caballero y Góngora (1771), después Arzobispo y virrey, en Boletín de la Real Academia de la Historia, 196 (1999), 261-326. 
colección de monedas, sino también el valor otorgado a la misma por parte de sus contemporáneos y el intercambio de información con éstos en pro del estudio de la Historia de España.

Como último aspecto a destacar en este apartado, así como remarcando el hecho de que la colección de monedas fue traída íntegramente a España en 1789, merece especial mención el hecho de que el 20 de enero de 1796, dos meses antes de su defunción, Caballero y Góngora expresó por escrito su voluntad de que la totalidad de su «monetario» fuera cedido al Real Colegio Mayor de Santa Catalina Mártir de la Universidad de Granada ${ }^{124}$ con el fin de favorecer la investigación histórica en dicho centro, al que estaba muy vinculado desde su juventud ${ }^{125}$. Cumpliendo su voluntad, el 4 de febrero de dicho año, Diego Carro, mayordomo y tesorero del prelado, hizo efectivo el traslado de la colección de monedas al citado colegio universitario granadino ${ }^{126}$, a excepción de un pequeño grupo de 160 piezas que quedaron en el Palacio Episcopal de Córdoba ${ }^{127}$. Este hecho especialmente significativo certifica el interés de nuestro protagonista por asegurar el destino final de su compendio numismático antes de su defunción, dado el valor del mismo.

\section{CONCLUSIONES}

Antonio Caballero y Góngora, una de las figuras más relevantes de la segunda mitad del siglo XVIII en el ámbito hispánico, destacó a lo largo de su vida por sus conocimientos, cultura, inventiva, habilidades sociales, oratoria, capacidades políticas, implicación e inquietudes; que lo erigieron como un representante público de los valores de la Ilustración y de los progresos que la introducción de los mismos suponían para el conjunto de la Monarquía española. Esta serie de cualidades definieron la personalidad de un individuo que dedicó parte impor-

124 AGOC, Expolios, 9645, exp. 10, s/f.

125 Institución donde, como se ha señalado al principio del artículo, estudió Caballero y Góngora durante la década de 1740 y con la que mantuvo especial contacto durante su etapa como obispo de Córdoba entre 1790 y 1796 a través de correspondencia personal con el rector de la misma, Joaquín Antonio de Luque. AGOC, Despachos ordinarios, 7137, exp. 1.

126 AGOC, Expolios, 9645, exp. 10, s/f. Legado que fue confirmado por el testimonio de Miguel Toledano y Alfonso (sobre el mismo véase la nota 78) en ARABASF, Secretario General, Académicos, Comunicaciones de fallecimientos y notas necrológicas, 1-47-2, Antonio Caballero y Góngora, ff. $14 \mathrm{r}-14 \mathrm{v}$.

127 AGOC, Expolios, 9646, exp. 4, ff. 252v-274v. 
tante de su tiempo a la recopilación razonada de aquellos objetos que sirvieran para ampliar sus conocimientos sobre las disciplinas que más inquietudes le despertaban, desarrollar su cultura estética y complacer sus intereses personales. De este modo, nuestro protagonista reunió a lo largo de su vida un extenso y variado «museo» que, compuesto por una amplia biblioteca de diverso contenido, una colección de arte notable, un conjunto de objetos singulares y un extraordinario compendio numismático; destacó tanto en España, como en América. Asimismo, dados los acontecimientos que marcaron la vida de Caballero y Góngora, estamos ante una colección de ida y vuelta que adquirió un valor único por su contenido y por el enriquecimiento que supuso su reproducción, préstamo, cesión o legado para diferentes instituciones y personalidades a ambos lados del Atlántico. Por todo ello, se trata de un conjunto de bienes que representa la personalidad plenamente ilustrada de un eclesiástico español que contribuyó al desarrollo del conocimiento, del Arte, de la Historia y de la Ciencia no sólo mediante su labor como prelado, político o militar, sino también por medio de su valiosa colección. Un caso paradigmático del coleccionismo de la razón, la recopilación del saber y el patrimonio personal al servicio del conocimiento ilustrado.

\section{REFERENCIAS BIBLIOGRÁFICAS}

\section{Archivisticas}

Córdoba, Archivo de la Catedral de Córdoba, Actas Capitulares, 94.

CóRDOba, ARCHIVO GENERAL DEL OBISPADO DE CóRDOba [= AGOC], Expolios, 9645, 9646, 9647, 9648. Despachos ordinarios, 7137.

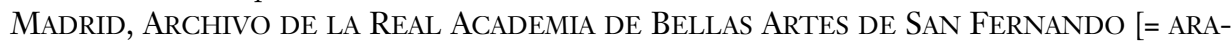
BASF], Secretario General: Académicos de Honor, Nombramientos, 1-40-5; Académicos, Comunicaciones de fallecimientos y notas necrológicas, 1-47-2, Antonio Caballero y Góngora; Enseñanza, Pensionados, 1-48-1, José Álvarez. Biblioteca, Adquisiciones, 1-24-1.

MAdRid, Biblioteca NACIONAL DE ESPAÑa [= BNE], Mss $/ 2537$.

SimanCaS, ARChIVo General DE SimanCAS, Secretaria de Estado y del Despacho de Guerra, Francisco Gil Lemos: Virrey, 7083-1.

\section{Bibliográficas}

Constituciones de la Real y Distinguida Orden Española de Carlos Tercero, Madrid, 1771. Instrucción a los Príncipes, sobre la política de los Padres jesuitas, Madrid, 1768.

Memorias sobre el exercicio discreto de la virtud de la Caridad en el repartimiento de la Limosna, Madrid, 1784. 
Real Ordenanza para el régimen y gobierno de la cría de caballos de raza en los Reynos de Andalucia, Murcia y Provincia de Extremadura, Madrid, 1775.

Recopilacion de leyes de los reynos de las Indias, 9 t., Madrid, 1756.

AgRICOLAE, Georgii, De re metallica, Basilea, 1561.

AgUilar PIÑal, Francisco, Bibliografía de autores españoles del siglo XVIII, 10 t., Madrid, 1981 2001.

AmaYA, José Antonio, Bibliografía de la Real Expedición Botánica del Nuevo Reino de Granada, Bogotá, 1983.

ANGUlO ÍÑIGUEZ, Diego, Murillo y su escuela en colecciones particulares, Sevilla, 1975.

ARANDA DONCEL, Juan, Un proyecto ilustrado en la Córdoba del siglo XVIII: La Escuela de Bellas Artes del obispo Caballero y Góngora, en Aphoteca, 6 (1986), pp. 33-49.

Arias Montano, Benito, Biblia Sacra. Hebraice, Chaldaice, Grece, \& Latine, 8 t., Amberes, 1568-1572.

ARIAS DE SAAVEDRA ALÍAS, Inmaculada, Libros extranjeros en bibliotecas privadas españolas del siglo XVII, en Agustín GUIMERÁ RAVINA y Víctor PERALTA RUIZ (coords.), Actas de la VIII Reunión Científica de la Fundación Española de Historia Moderna, 2 t., Madrid, 2005, t. 2, pp. 395-416.

- Libros, lectores y bibliotecas privadas en la España del siglo XVIII, en Chronica Nova, 35 (2009), pp. 15-61.

BERLEKAMP, Friederike, Acerca de la investigación del arte plumario colonial de Sudamérica. Posibilidades y perspectivas de la Cultura visual bistórica en un contexto intercultural, en Diálogo Andino, 49 (2016), pp. 113-122.

BLONDEL, Jacques Francois, Cours d'architecture civile, 6 t., Paris, 1771-1777.

Bonilla, Heraclio, Las minas de Mariquita en el Nuevo Reino de Granada: Minería, mano de obra y circulación monetaria en los Andes del siglo XVII, Madrid, 2015.

BuRgos Rincón, Francisco Javier, Los libros privados del clero: La cultura del libro del clero barcelonés en el siglo XVIII, en Manuscrits: Revista d'bistoria moderna, 14 (1996), pp. 231258.

Butron, Iván de, Discursos apologeticos en que se defiende la ingenuidad del arte de la pintura, Madrid, 1626.

CABEllo Carro, María Paz, Coleccionismo americano indígena en la España del siglo XVIII, Madrid, 1989.

- La formación de las colecciones americanas en España. Evolución de los criterios, en Anales del Museo de América, 9 (2001), pp. 303-318.

CAMPOS Y FERNÁNDEZ DE SEVILLA, F. Javier, Epistolario ilustrado: La correspondencia del Agustino P. Enrique Flórez con D. Pedro Leonardo de Villacevallos (1744 a 1759), y D. Antonio Caballero y Góngora (1771), después Arzobispo y virrey, en Boletín de la Real Academia de la Historia, 196 (1999), 261-326.

Campos y FernándeZ de Sevilla, F. Javier, El P. Flórez y los estudios de la Historia Antigua de España en el reinado de Carlos III (1759-1788), en Cuadernos de Investigación Histórica, 27 (2010), pp. 23-63.

CEDILlo, Pedro Manuel, Trigonometria aplicada a la Navegacion, Sevilla, 1718. 
CRUZ AlCAÑIZ, Cándido de la, La imagen del Arzobispo y Cardenal Francisco Antonio de Lorenzana, en Archivo Español de Arte, 329 (2010), pp. 41-60.

DEIDIER, Le parfait Ingénieur Francois, ou La Fortification offensive et défensive, Amsterdam, 1734.

Duhamel de Monceau, Éléments d'Agriculture, 2 t., Paris, 1762.

ENCISO RECIO, Luis Miguel, Barroco e Ilustración en las bibliotecas privadas españolas del siglo XVIII, Madrid, 2002.

FERNÁNDEZ, Andrés, Instrvccion de Enfermeros, Madrid, 1625.

FLEURY, Claude, Histoire ecclésiastique, 36 t., Paris, 1719-1734.

FlOREZ, Henrique, Medallas de las Colonias, Municipios y pueblos antiguos de España, 3 t., Madrid, 1757-1773.

FONTAINE, Jean de la, Fabulas Morales Escogidas, Madrid, 1787.

FRANCO, Francisco de, Tratado de la Nieve y del uso della, Sevilla, 1569.

FrANKL, Víctor, La filosofía política del Arzobispo-Virrey de Nueva Granada Antonio Caballero y Góngora, en Bolivar, 1 (1951), pp. 113-129.

- La estructura barroca del pensamiento político, bistórico y económico del Arzobispo-Virrey de Nueva Granada Antonio Caballero y Góngora, en Bolivar, 5 (1951), pp. 805-873.

- La filosofía social tomista del arzobispo-virrey del Nuevo Reino de Granada, Caballero y Góngora y la de los comuneros colombianos, en Bolívar, 15 (1952), pp. 595-626.

García Felguera, María de los Santos, La fortuna de Murillo (1682-1900), Sevilla, 1989.

GIL-DíEZ UsandiZaga, Ignacio, Sebastián Martínez, el amigo de Goya, en Brocar, 18 (2014), pp. 197-209.

GLAIRE, Jean-Baptiste, Dictionnaire Universel des Sciences Ecclésiastiques, 2 t., Paris, 1868.

GómeZ y GómeZ, Tomás, Vida y obra de Don Antonio Caballero y Góngora, Sevilla, 1989.

GÓNGORA, Luis de, Obras, 3 t., Madrid, 1633.

GranadA, Fray Luis de, Obras, 12 t., Pamplona, 1780.

Houdry, Vincent, La Bibliothèque des Prédicateurs, 21 t., Lyon, 1724-1743.

Lancillotto, Gabriele, Alla Sicilia Numismatica di Filippo Paruta, Palermo, 1770.

LASTANOSA, Vicencio Juan de, Museo de las medallas desconocidas españolas, Huesca, 1645.

LE BLOND, M., Traité de l'attaque des places, Paris, 1762.

LEDIARD, Thomas, Histoire Navale d'Angleterre, Lyon, 1751.

LÓPEZ-VIDRIERO, Maria Luisa, El Gabinete de un hombre de gusto. Manuales para la formación de bibliotecas en el siglo XVIII, en María Luisa LóPEZ-VIDRIERO (dir.) y Pedro M. CÁTEDRA (dir.), El Libro Antiguo Español IV. Coleccionismo y bibliotecas (siglos XV-XVIII), Salamanca, 1998, pp. 447-460.

MaChIAVELLI, Nicolas, Les Discours de l'Estat de Paix et de guerre, Madrid, 1579.

MARQUEZ, Ioan, El Gobernador Christiano, Madrid, 1625.

MARTÍNEZ, Manuel, Obligaciones de los Amos y de los Criados, escritas en francés por el mui ilustre señor Claudio Fleuri, Madrid, 1771.

MEjÍA, Pedro, Historia Imperial y Cesarea, Madrid, 1655.

Montargon, Hyacinthe de, Dictionnaire Apostolique, 13 t., Paris, 1752-1758.

MONTES GONZÁLEZ, Francisco, Una aproximación a las fuentes documentales para el estudio del coleccionismo americano en España, en Artigrama, 24 (2009), pp. 205-223. 
MORA MÉRIDA, José Luis, Ideario reformador de un cordobés ilustrado: el Arzobispo y Virrey don Antonio Caballero y Góngora, en Bibiano TORREs RamíreZ y José J. HernándEZ PaLOMO (coords.), Andalucía y América en el siglo XVIII: actas de las IV Jornadas de Andalucía y América, 2 t., Sevilla, 1985, t. 2, pp. 233-260.

Mora Serrano, Bartolomé, Las monedas, en José Beltrán ForTeS y José Ramón LóPEZ RODRíguez (coords.), El museo cordobés de Pedro Leonardo de Villacevallos, Madrid, 2003, pp. 219-322.

MORALES, Alfredo J., Murillo restaurador y Murillo restaurado, en Archivo Español de Arte, 240 (1987), pp. 475-480.

MORAlEs GÓmEZ, Jorge, Notas etnográficas sobre la tecnología de los indios cuna, en Revista Colombiana de Antropopología, 19 (1975), pp. 79-102.

MuTIS, José Celestino, Diario de observaciones de fosé Celestino Mutis (1760-1790), Bogotá, 1957.

NADAL INIESTA, Javier, El mobiliario doméstico en la Murcia de principios del siglo XVIII (17001725), en Imafronte, 18 (2016), pp. 93-103.

Navarrete Prieto, Benito y García DE la TORre, Fuensanta, Antonio del Castillo en la senda del Naturalismo, Córdoba, 2016.

NeWTON, Isaac, Philosophiae Naturalis Principia Mathematica, Londres, 1726.

Nieto Cumplido, Manuel, La Catedral de Córdoba, Córdoba, 1998.

Peláez del Rosal, Manuel, Rey Díaz, Jose María y Tisnes Jiménez, Roberto María, El Obispo Caballero, un prieguense en América, Priego de Córdoba, 1989.

PÉREZ AYala, José Manuel, Antonio Caballero y Góngora. Virrey y Arzobispo de Santa Fé. $1723-$ 1796, Bogotá, 1951.

PÉREZ BAYER, Francisco, Del alfabeto de los fenicios y de sus colonias, Madrid, 1772.

PÉREZ LóPEZ, Nerea Virginia, Murillo y los orígenes de la iconografía del Niño fesús dormido sobre la cruz, en Boletín de Arte, 36 (2015), pp. 145-154.

PÉREZ SÁNCHEZ, Alfonso Emilio, Pintura italiana del siglo XVII en España, Madrid, 1965.

PhILANDrIER, Guillaume, M. Vitruvij Polionis De Architectura Libri X, Lyon, 1552.

PONZ, Antonio, Viage de España, 18 t., Madrid, 1772-1794.

PorTugues, Joseph Antonio, Coleccion general de las Ordenanzas militares, 11 t., Madrid, 1764-1768.

RESTREPO TIRADO, Ernesto, La fortuna del excelentísimo señor don Antonio Caballero y Góngora, en Boletín de Historia y Antigüedades, 177 (1926), pp. 567-571.

REVENGa DOMÍNGUEZ, Paula, El coleccionismo ilustrado del cardenal Lorenzana entre España y México, en Oscar FloRes Flores (coord.), El Clasicismo en la época de Pedro fosé Márquez (1741-1820), México, 2014, pp. 205-221.

REY DíAZ, José María, D. Antonio Caballero y Góngora. Arzobispo-Virrey de Nueva Granada (I), en Boletín de la Real Academia de Ciencias, Bellas Artes y Nobles Artes de Córdoba, 4 (1923), pp. 63-83.

- D. Antonio Caballero y Góngora. Arzobispo-Virrey de Nueva Granada (II), en Boletín de la Real Academia de Ciencias, Bellas Artes y Nobles Artes de Córdoba, 5 (1923), pp. 5-33.

RICHELIEU, Le politique tres-christien ou Discours politiques, Paris, 1645.

RoA, Martin de, Antiguo Principado de Cordova En la España Ulterior o Andaluz, Córdoba, 1636.

\section{0}


RoDríguEZ, Nelson Eduardo, El imperio contraataca: las expediciones militares de Antonio Caballero y Góngora al Darién (1784-1790), en Historia Crítica, 53 (2014), pp. 201-223.

Rodríguez CASANOVA, Isabel, La numismática en la España de la Ilustración, en Martín ALMAGRo Gorbea y Jorge MAIER Allende (coords.), De Pompeya al Nuevo Mundo. La corona española y la arqueología en el siglo XVIII, Madrid, 2012, pp. 157-172.

Rose Wagner, Isadora Joan, Manuel Godoy Patrón de las Artes y Coleccionista, Madrid, 1983.

RUSSO, Alessandra, El encuentro de dos mundos artísticos en el arte plumerío mexicano del siglo XVI, en Probistoria: Historia, políticas de la Historia, 2 (1998), pp. 63-91.

SALAS ÁlVAREZ, Jesús, El coleccionismo numismático en Andalucía durante la Ilustración, en Nvmisma, 252 (2008), pp. 149-176.

SAN GERÓNIMO, Sor Ana de, Obras poéticas, Córdoba, 1773.

SANTiago PÁEZ, Elena María (dir.), Ceán Bermudez. Historiador del arte y coleccionista ilustrado, Madrid, 2016.

Sierra NAVA-LASA, Luis, El Cardenal Lorenzana y la Ilustración, Madrid, 1975; Jesús PANIAGUA PÉREZ (coord.), España y América entre el Barroco y la Ilustración (1722-1804). II Centenario de la muerte del Cardenal Lorenzana, León, 2005.

SiLva, Renán, Los ilustrados de Nueva Granada, 1760-1808, Medellín, 2002.

SOUBEYROUX, Jacques, La biblioteca de Campomanes: contexto cultural de un ilustrado, en Actas del Séptimo Congreso de la Asociación Internacional de Hispanistas, 2 t., Roma, 1982, t 2, pp. 9971006.

TiSnes JimÉNEZ, Roberto María, Caballero y Góngora y los Comuneros, Bogotá, 1984.

TOFIÑO DE SAN Miguel, Vicente, Observaciones astronómicas hechas en Cádiz, en el obsertario Real de la Compañia de Cavalleros Guardias-Marinas, Cádiz, 1776.

Toledano, Francisco de Paula, Oración panegírica, e bistorial, en justa memoria del Excmo. è Illmo. Señor Don Antonio Caballero y Gongora, Granada, 1798.

TORRe Revello, José, La biblioteca del virrey-arzobispo del Nuevo Reino de Granada Antonio Caballero y Góngora, 1788, en Boletín del Instituto de Investigaciones Históricas, 41 (1929), pp. $27-45$.

- Tratados de Arquitectura utilizados en Hispanoamérica (siglos XVI a XVIII), en Revista Interamericana de Bibliografía, 6 (1956), pp. 3-23.

ToscA, Thomas Vicente, Compendio Mathematico, en que se contienen todas las materias mas principales de las Ciencias, que tratan de la Cantidad, 9 t., Valencia, 1757.

TOWNELEY, John, Biblioteca Towneleiana. A catalogue of the curious and extensive library of the late Fohn Towneley, 2 t., Londres, 1814-1815.

Trelles Villademoros, Jose Manuel, Asturias ilustrada. Historia chronológica y genealógica del primitivo origen de la nobleza de España, su antigüedad, clases y diferencias, con sucessiones continuadas de las principales familias del Reyno, y con la ilustración del Principado de Asturias, 8 t., Madrid, 1760.

UREÑA UCEDA, Alfredo, La pintura andaluza en el coleccionismo de los siglos XVII y XVIII, en Cuadernos de Arte e Iconografía, 13 (1998), pp. 99-148.

Urriagli Serrano, Diana, Coleccionismo de Pintura en España en la segunda mitad del siglo XVIII, en Luis SAZATORNIL RUIZ (ed.) y Frédéric JiMÉNO (ed.), El arte español entre Roma y París (siglos XVIII y XIX), Madrid, 2014, pp. 239-256. 
URRÍES Y DE LA COCINA, Javier Jordán de, El coleccionismo del ilustrado Bernardo Iriarte, en Goya, 319-320 (2007), pp. 259-280.

VAILLANT, Joannes, Numismata imperatorum romanorum praestantiora, a Iulio Caesare ad lostumum et tyrannos, Paris, 1674.

- Numismata Graeca, Amsterdam, 1700.

- Historia numismática Ptolemaeorum Aegypti regum, Amsterdam, 1701.

- Historia numismática Regum Syriae, La Haya, 1732.

VELAZQUEZ, Luis Joseph, Ensayo sobre los alfabetos de las Letras Desconocidas, Que se encuentran en las mas antiguas medallas, y Monumentos de España, Madrid, 1752.

- Congeturas sobre las Medallas de los Reyes Godos y Suevos de España, Málaga, 1759.

VELEZ MARIN, Manuel, Disertacion sobre las letanias antiguas de la Iglesia de España, Madrid, 1758.

Venegas, Miguel, Noticia de la California y de su conquista temporal y espiritual hasta el tiempo presente, Madrid, 1757.

VILlate, Camilo y TAMAYO, Brando, Torre de oficinas Avianca, Bogotá, 2012.

YAYA, Isabel, Wonders of America: The curiosity cabinet as a site of representation and knowledge, en Fournal of the History of Collections, 20 (2008), pp. 173-188. 
0000 